\title{
Multiwall carbon nanotube paste electrode with 3,4-dihydroxy-cinnamic acid as mediator for the determination of glutathione in pharmaceutical and urine samples
}

\author{
Mohsen Keyvanfard a,*, Hassan Karimi-Maleh b, Khadijeh Alizad ${ }^{a}$ \\ a Department of Chemistry, Majlesi Branch, Islamic Azad University, Isfahan, Iran \\ ${ }^{\mathrm{b}}$ Department of Chemistry, Graduate University of Advanced Technology, Kerman, Iran
}

\section{A R T I C L E I N F O}

\section{Article history:}

Received 10 May 2013

Accepted 12 July 2013

Published 20 October 2013

Keywords:

Glutathione

3,4-Dihydroxy-cinnamic acid

Carbon paste electrode

Multiwall carbon nanotube

Sensor

\begin{abstract}
A B S T R A C T
A sensitive and selective electrochemical sensor for the determination of glutathione (GSH) was developed using a modified multiwall carbon nanotube paste electrode with 3,4-dihydroxy-cinnamic acid as a mediator. This modified electrode showed very high electrocatalytic activity for the anodic oxidation of GSH. Under the optimized conditions, the electrocatalytic peak current showed a linear relationship with GSH concentration in the range of $0.5-400.0 \mu \mathrm{mol} / \mathrm{L}$ with a detection limit of $0.1 \mu \mathrm{mol} / \mathrm{L} \mathrm{GSH}$. The relative standard deviations for seven successive assays of 5.0 and 25.0 $\mu \mathrm{mol} / \mathrm{L}$ GSH were $2.2 \%$ and $2.7 \%$, respectively. The modified electrode was used for the determination of GSH compounds in real urine samples.
\end{abstract}

(C) 2013, Dalian Institute of Chemical Physics, Chinese Academy of Sciences. Published by Elsevier B.V. All rights reserved.

\section{Introduction}

Glutathione (GSH) is a biological thiol compound that is the main intracellular tripeptide in mammals. Its role in human metabolism includes protection against oxidative stress and detoxification of xenobiotics [1]. Changes in its concentration in biological fluids or tissues are a useful marker of certain disorders such as leukemia [2], diabetes [3], DNA base damages [4] and in the investigation of some kinds of cancer [5]. A number of methods have been proposed for the determination of GSH including titrimetry [6], spectrophotometry [7,8], spectrofluorimetry [9], high performance liquid chromatography [10-12], capillary zone electrophoresis $[13,14]$, proton nuclear magnetic resonance (1H NMR) [15,16], and enzymatic [17] and electrochemical methods [18-22]. Electrochemical methods have shown significant advantages in the analysis of different compounds in biological and pharmaceutical samples. These ad- vantages are mainly attributable to the simplicity, low cost and relatively short analysis times of these compounds as compared to chromatography and other methods [23]. In recent years, chemically modified electrodes have attracted much notice due to their potential applications in various analyses $[24,25]$.

Carbon nanotubes (CNTs) have a novel type of nanostructure with unique structural electronic and mechanical properties and have been studied extensively since their discovery [26-28]. Research over the past decade has revealed that the CNTs constituted a new form of carbon materials that are finding striking applications in many fields, such as energy conversion and storage [29], chemical actuators [30,31], and chemical sensing [32-36]. In the present work, we described the preparation of a multiwall carbon nanotube paste electrode (MWCNTPE) with 3,4-dihydroxy-cinnamic acid (3,4-DHCA) as a suitable sensor for the electrocatalysis and determination of

\footnotetext{
*Corresponding author. Tel: +98-913-1009952; Fax: +98-913-3355452356; E-mail: keyvan45638@yahoo.com This work was supported by Majlesi Branch, Islamic Azad University, Isfahan, Iran. 
GSH in aqueous buffer solution. The proposed method is selective, sensitive, and fast for the determination of GSH in real samples such as GSH tablets, urine, and hemolyzed erythrocyte.

\section{Experimental}

\subsection{Apparatus and reagents}

All the voltammetric measurements were performed using an Autolab PGSTAT 302N, potentiostat/galvanostat (Utrecht, The Netherlands) connected to a three-electrode cell, Metrohm (Herisau, Switzerland) Model 663 VA stand. This was operated by a computer (Pentium IV, $1200 \mathrm{MHz}$ ) with the Autolab software. A platinum wire was used as the auxiliary electrode. MWCNTPE and $\mathrm{Ag} / \mathrm{AgCl} / \mathrm{KCl}_{\text {sat }}$ were used as the working and reference electrodes, respectively. The electrode prepared with CNTs was characterized by scanning electron microscopy (SEM, Seron Tech. AIS 2100). A digital pH/mV meter (Metrohm model 710) was applied for $\mathrm{pH}$ measurements. Spectrally pure graphite powder (particle size $<50 \mu \mathrm{m}$ ) from Merck and multiwall carbon nanotubes ( $>90 \%$ MWCNTs basis, $d \times l=(90-70$ $\mathrm{nm}) \times(5-9 \mu \mathrm{m}))$ from Fluka were used for the preparation of the carbon paste electrode.

Phosphate buffer $\left(\mathrm{NaH}_{2} \mathrm{PO}_{4}-\mathrm{Na}_{2} \mathrm{HPO}_{4}-\mathrm{NaOH} 0.1 \mathrm{~mol} / \mathrm{L}\right)$ solutions (PBS) with different $\mathrm{pH}$ values were used. All chemicals used were analytic reagent grade purchased from Merck (Darmstadt, Germany) unless otherwise stated. Doubly distilled water was used throughout. GSH was from Fluka.

\subsection{Preparation of the electrode}

To eliminate any metal oxide catalyst in the nanotubes, the MWCNTs were refluxed in $2.0 \mathrm{~mol} / \mathrm{L} \mathrm{HNO}_{3}$ for $12 \mathrm{~h}$, and then washed with twice distilled water and dried at room temperature. Graphite powder (0.900 g) was dissolved in diethyl ether and hand mixed with $0.100 \mathrm{~g}$ CNTs in a mortar and pestle. The solvent was evaporated by stirring. A syringe was used to add paraffin to the mixture, which was mixed well for 40 min until a uniformly wetted paste was obtained. The paste was then packed into a glass tube. Electrical contact was made by pushing a copper wire down the glass tube into the back of the mixture. When necessary, a new surface was obtained by pushing an excess of the paste out of the tube and polishing it on a weighing paper.

\subsection{Preparation of real samples}

Human whole blood was obtained from the Majlesi Health Center and erythrocytes were separated from the whole blood by removing the plasma. The human whole blood $(2.0 \mathrm{~mL})$ was first centrifuged for $10 \mathrm{~min}$ at $3000 \mathrm{r} / \mathrm{min}$. The supernatant (plasma) was discarded and the remainder was mixed with 5 $\mathrm{mL}$ of $0.9 \% \mathrm{NaCl}$ solution. The solution was centrifuged for another $5 \mathrm{~min}$ at $3000 \mathrm{r} / \mathrm{min}$ and the supernatant (diluted plasma) was again discarded. The washing procedure with $\mathrm{NaCl}$ solution was repeated three times to remove the plasma almost completely.
The erythrocyte pellets were hemolyzed with water (1:1, $\mathrm{v} / \mathrm{v}$ ). For protein precipitation, the hemolysate was mixed with 5 -sulfosalysilic acid $(10 \%, \mathrm{~m} / \mathrm{v})$ in the ratio of $2: 1(\mathrm{v} / \mathrm{v})$. This mixture was centrifuged under the same conditions described above. Then, the supernatant was divided to two parts: one for spectrophotometric determination and another for the proposed electrochemical method. For spectrophotometric measurements with a reference method [37], the Ellman method was used, which is based on the reaction of GSH and DTNB (Ellman's reagent) to generate 2-nitro-5-mercapto-benzoic acid. The absorbance was monitored spectrophotometrically at $412 \mathrm{~nm}$.

The urine samples were stored in a refrigerator immediately after collection. The sample (10 mL) was centrifuged for 20 $\min$ at $2000 \mathrm{r} / \mathrm{min}$. The supernatant was filtered using a 0.45 $\mu \mathrm{m}$ filter and then diluted 5 fold with PBS ( $\mathrm{pH}$ 7.0). The solution was transferred into the voltammetric cell for analysis without any further pretreatment. The standard addition method was used for the determination of GSH in real samples.

The tablet solution was prepared by completely grinding and homogenizing seven tablets of GSH, labeled to have $100 \mathrm{mg}$ per tablet (Chongqing Yaoyou Pharmaceutical Co., Ltd., China). Then, $10 \mathrm{mg}$ of each tablet powder was accurately weighed and dissolved in $100 \mathrm{~mL}$ water by ultrasonication. After mixing completely, the mixture was filtered on an ordinary filter paper, $10 \mathrm{~mL}$ of which was subsequently transferred into a $100 \mathrm{~mL}$ volumetric flask and diluted to the mark with water. Then, 1.0 $\mathrm{mL}$ of the solution plus $4.5 \mathrm{~mL}$ of the buffer ( $\mathrm{pH} 7.0$ ) was used for analysis using the standard addition method.

\subsection{Optimization of 3,4-DHCA concentration}

The influence of 3,4-DHCA concentration on the electrocatalytic oxidation peak current was studied at two different concentrations of GSH at $\mathrm{pH} 5.0$, and in the range of 100.0 to 700 $\mu \mathrm{mol} / \mathrm{L} 3,4-\mathrm{DHCA}$. The results showed that by increasing the concentration of 3,4-DHCA up to $500 \mu \mathrm{mol} / \mathrm{L}$ the peak current increased, while higher concentrations of 3,4-DHCA caused a slight decrease in the magnitude of the peak current, which may be due to the formation of 3,4-DHCA aggregates. Therefore, $500 \mu \mathrm{mol} / \mathrm{L}$ 3,4-DHCA concentration was selected for further studies.

\section{Results and discussion}

\subsection{SEM characterization}

Figure 1 shows SEM images of the MWCNTPE and carbon paste electrodes (CPE). As can be seen at the surface of CPE, layers of irregular flakes of graphite powder were present that were isolated from each other. After MWCNTs were added to carbon paste, it can be seen that MWCNTs were distributed on the surface of electrode with a special three dimensional structure, indicating that the MWCNTs were successfully assimilated on the MWCNTPE.

\subsection{Electrochemistry of 3,4-DHCA}




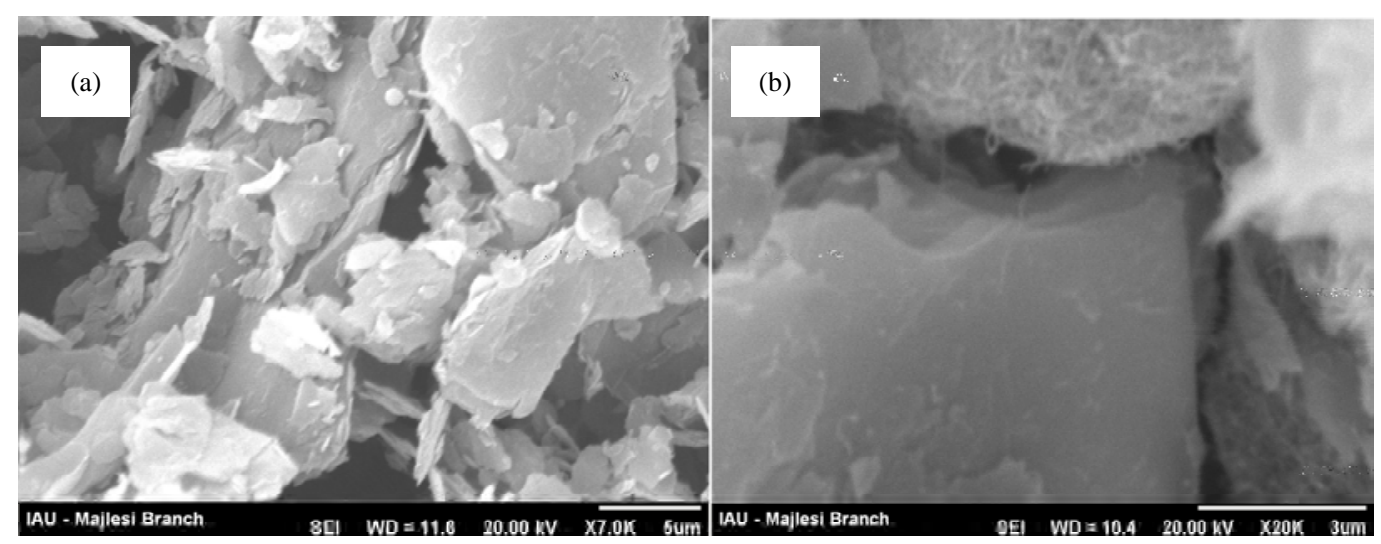

Fig. 1. SEM images of CPE (a) and MWCNTPE (b).

The cyclic voltammograms of 3,4-DHCA at the surface of MWCNTPE in 0.1 mol/L PBS (pH 5.0) are shown in Fig. 2(a). As can be seen, the cyclic voltammogram exhibited an anodic peak at the forward scan of the potential related to the oxidation of $3,4-\mathrm{DHCA}_{\text {(red) }}$ to $3,4-\mathrm{DHCA}_{(\mathrm{ox})}$. In the reverse scan of the potential, a cathodic peak appeared, which was related to the reduction of 3,4-DHCA(ox) to 3,4-DHCA(red). A pair of quasi-reversible peaks were observed at $E_{\mathrm{pa}}=0.30 \mathrm{~V}$ and $E_{\mathrm{pc}}=0.17 \mathrm{~V}$ versus $\mathrm{Ag} / \mathrm{AgCl}$. The half-wave potential $\left(E_{1 / 2}\right)$ was $0.24 \mathrm{~V}$ versus $\mathrm{Ag} / \mathrm{AgCl}$ and $\Delta E_{\mathrm{p}}\left(E_{\mathrm{pa}}-E_{\mathrm{pc}}\right)$ was $0.13 \mathrm{~V}$. The electrode process was quasi-reversible, with $\Delta E_{\mathrm{p}}$, greater than the expected value $(59 / \mathrm{n} \mathrm{mV})$ for a reversible system. The plot of the anodic peak current was linearly dependent on $v^{1 / 2}$ for all scan rates (Fig. 2(b)). This behavior indicated that the nature of the redox pro-
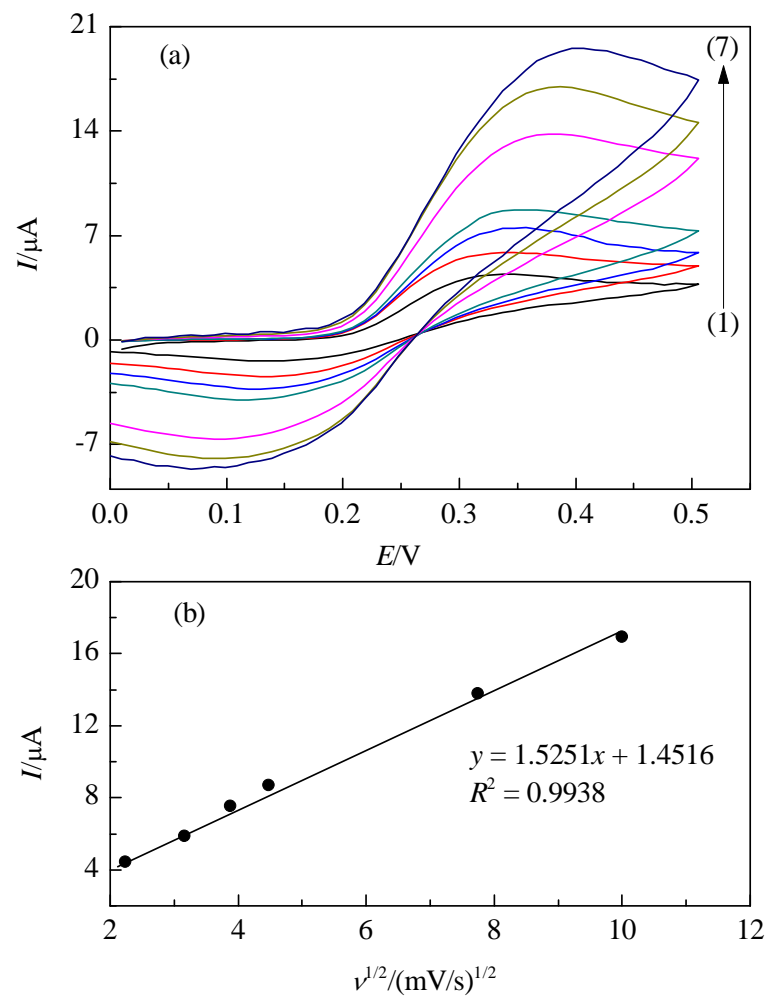

Fig. 2. (a) Cyclic voltammograms at various scan rates in $0.1 \mathrm{~mol} / \mathrm{L}$ PBS (pH 5.0): (1) $5 \mathrm{mV} / \mathrm{s}$; (2) $10 \mathrm{mV} / \mathrm{s}$; (3) $15 \mathrm{mV} / \mathrm{s}$; (4) $20 \mathrm{mV} / \mathrm{s}$; (5) 60 $\mathrm{mV} / \mathrm{s}$; (6) $100 \mathrm{mV} / \mathrm{s}$. (b) Plot of $I_{\mathrm{pa}}$ versus $v^{1 / 2}$ for the oxidation of 500 $\mu \mathrm{mol} / \mathrm{L} 3,4-\mathrm{DHCA}$ at a surface of MWCNTPE. cess is diffusion controlled.

The active surface areas of the modified electrodes were estimated from the slope of the $I_{\mathrm{p}}$ versus $v^{1 / 2}$ plot for a known concentration of $\mathrm{K}_{2} \mathrm{Fe}(\mathrm{CN})_{6}$, based on the Randles-Sevcik equation [38]:

$$
I_{\mathrm{p}}=2.69 \times 105 n^{3 / 2} A D_{\mathrm{R}}^{1 / 2} v^{1 / 2} C_{0}
$$

where $I_{\text {pa }}$ refers to the anodic peak current, $n$ is the electron transfer number, $A$ refers to the surface area of the electrode, $D_{\mathrm{R}}$ is the diffusion coefficient, $C_{0}$ refers to the concentration of $\mathrm{K}_{2} \mathrm{Fe}(\mathrm{CN})_{6}$, and $v$ is the scan rate. For $1.0 \mathrm{mmol} / \mathrm{L} \mathrm{K}_{2} \mathrm{Fe}(\mathrm{CN})_{6}$ in $0.10 \mathrm{~mol} / \mathrm{L} \mathrm{KCl}$ electrolyte with $n=1$ and $D_{\mathrm{R}}=7.6 \times 10^{-6} \mathrm{~cm} / \mathrm{s}$, from the slope of the $I_{\mathrm{pa}}-v^{1 / 2}$ curve, the areas were calculated. The active surface areas were 0.08 and $0.13 \mathrm{~cm}^{2}$ for CPE and MWCNTPE, respectively. The result showed that the presence of MWCNTPE gave an increase in the active surface of the electrode.

\subsection{Electrocatalytic oxidation of GSH}

Figure 3(1) shows the voltammetric behavior of 3,4-DHCA in the buffer solution ( $\mathrm{pH} 5.0)$. The cyclic voltammetric responses for the electrochemical oxidation of $150 \mu \mathrm{mol} / \mathrm{L}$ of

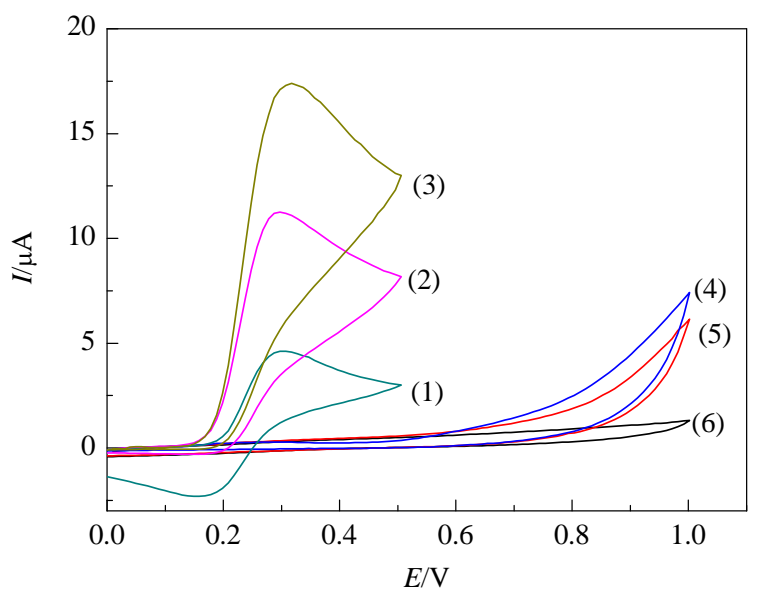

Fig. 3. Cyclic voltammograms of $500 \mu \mathrm{mol} / \mathrm{L} 3,4-\mathrm{DHCA}$ at the surface of MWCNTPE and CPE in $0.1 \mathrm{~mol} / \mathrm{L} \mathrm{PBS} \mathrm{(pH} \mathrm{5.0)} \mathrm{at} \mathrm{a} \mathrm{scan} \mathrm{rate} \mathrm{of} 20 \mathrm{mV} / \mathrm{s}$. (1) In the absence of GSH at MWCNTPE; (2) In the presence of 150 $\mu \mathrm{mol} / \mathrm{L}$ GSH at CPE; (3) In the presence of $150 \mu \mathrm{mol} / \mathrm{L} \mathrm{GSH} \mathrm{AT} \mathrm{CPE;} \mathrm{(4)}$ as (3) and (5) as (2) for the in the absence of 3,4-DHCA; (6) In the absence of GSH and 3,4-DHCA at MWCNTPE. 
GSH at the surface of MWCNTPE (Fig. 3(3)), and at the surface of the CPE (Fig. 3(2)) in the presence of the mediator. On the other hand, Fig. 3(4) and (5) are in the absence of 3,4-DHCA. As can be seen, the anodic peak potentials for the oxidation of GSH at MWCNTPE (Fig. 3(3)) and CPE (Fig. 3(2)) in the presence of mediator are $300 \mathrm{mV}$. Note that GSH oxidation at the surface of MWCNTPE (without the mediator, Fig. 3(4)), and at the surface of CPE (without the mediator), did not take place at the surface of the CNTPE up to $+1.00 \mathrm{~V}$. As can be seen, the electroactivity of GSH on the MWCNTPE and CPE in the presence of the mediator was significant, with a strongly defined peak potential around $300 \mathrm{mV}$ versus the $\mathrm{Ag} / \mathrm{AgCl} / \mathrm{KCl}_{\text {sat }}$ electrode. Thus, a decrease in the over-potential and enhancement of the peak current for GSH oxidation were achieved with the MWCNTPE and CPE in the presence of the mediator. Such behavior is indicative of an electrocatalytic mechanism (see Scheme 1) [39-42]. Similarly, when we compared the oxidation of GSH at the surface of MWCNTPE and CPE with mediator, it was observed that a dramatic enhancement of the anodic peak current occurred at MWCNTPE versus the value obtained with CPE. As can be seen, in the presence of the mediator, oxidation of GSH can occur at the potential of the mediator, and the MWCNTs increased the oxidation current of it. These results clearly showed that the combination of MWCNTPE and the mediator (3,4-DHCA) definitely improved the characteristics of the electrode for the oxidation of GSH.

The effect of scan rate on the electrocatalytic oxidation of $200 \mu \mathrm{mol} / \mathrm{L} \mathrm{GSH}$ at the modified electrode was investigated by linear sweep voltammetry (Fig. 4(a)). The oxidation peak potential shifted with increasing scan rates towards a more positive potential, confirming the kinetic limitation of the electrochemical reaction. Also, a plot of peak height $\left(I_{\mathrm{p}}\right)$ against the square root of scan rate $\left(\nu^{1 / 2}\right)$ in the range $2-30 \mathrm{mV} / \mathrm{s}$ was constructed, which was found to be linear, suggesting that at a sufficient overpotential, the process is diffusion rather than surface reaction controlled (Fig. 4(b)).

To obtain further information on the rate determining step, a Tafel plot was developed for the GSH measurement at the

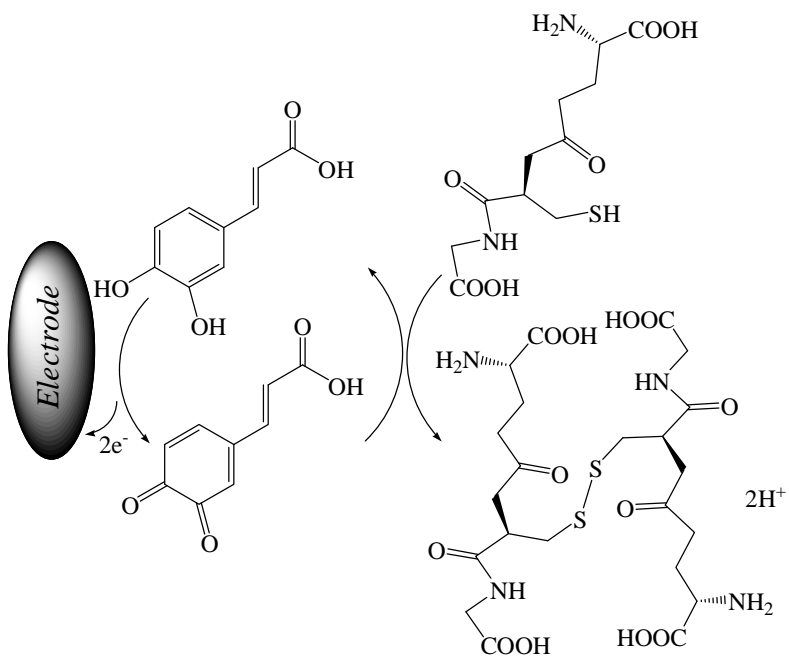

Scheme 1. Electrocatalytic mechanism for the determination of GSH at the surface of MWCNTPE in the presence of the mediator.
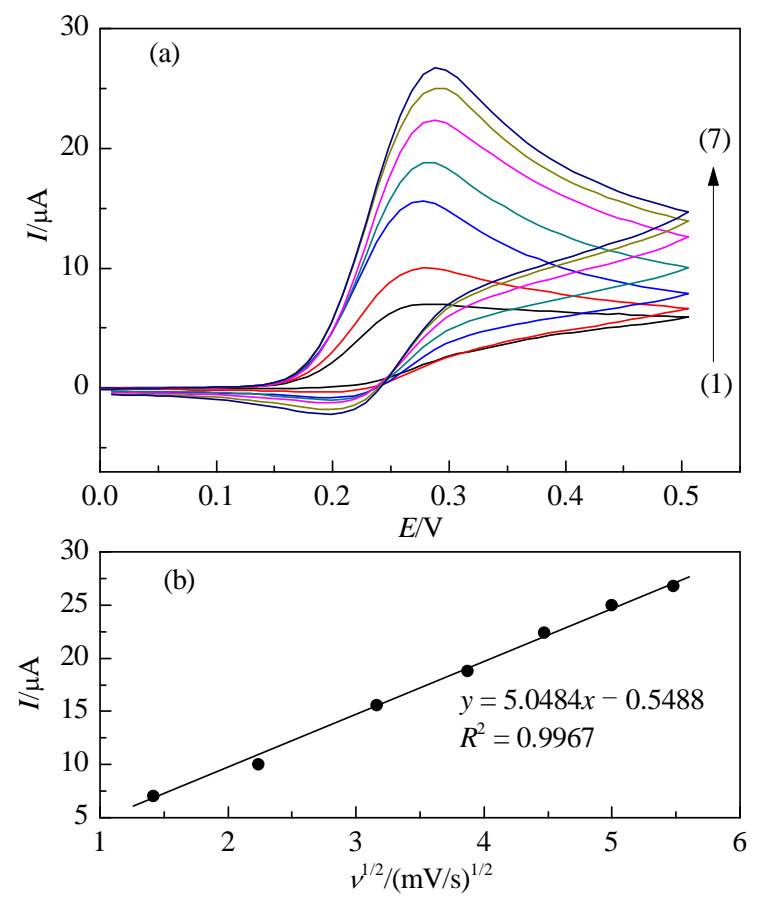

Fig. 4. (a) Cyclic voltammograms of $200 \mu \mathrm{mol} / \mathrm{L}$ GSH in the presence of $500 \mu \mathrm{mol} / \mathrm{L} \mathrm{3,4-DHCA}$ at various scan rates in $0.1 \mathrm{~mol} / \mathrm{L}$ PBS (PH 5.0 ). (1) $2 \mathrm{mV} / \mathrm{s}$; (2) $5 \mathrm{mV} / \mathrm{s}$; (3) $10 \mathrm{mV} / \mathrm{s}$; (4) $15 \mathrm{mV} / \mathrm{s}$; (5) $20 \mathrm{mV} / \mathrm{s}$; (6) 25 $\mathrm{mV} / \mathrm{s}$; (7) $30 \mathrm{mV} / \mathrm{s}$. (b) Plot of $I_{\mathrm{pa}}$ versus $v^{1 / 2}$ for the oxidation of 200 $\mu \mathrm{mol} / \mathrm{LGSH}$ in the presence of $500 \mu \mathrm{mol} / \mathrm{L} 3,4-\mathrm{DHCA}$ at the surface of MWCNTPE.

MWCNTPE in the presence of the mediator using the data derived from the rising part of the current-voltage curve (Fig. $5(\mathrm{a}))$. The slope of the Tafel plot is equal to $n(1-\alpha) F / 2.3 R T$, which comes to $0.0899 \mathrm{~V}$ decade ${ }^{-1}$. We obtained $n_{\alpha}$ as 0.35 . Assuming $n=1$, then $\alpha=0.35$.
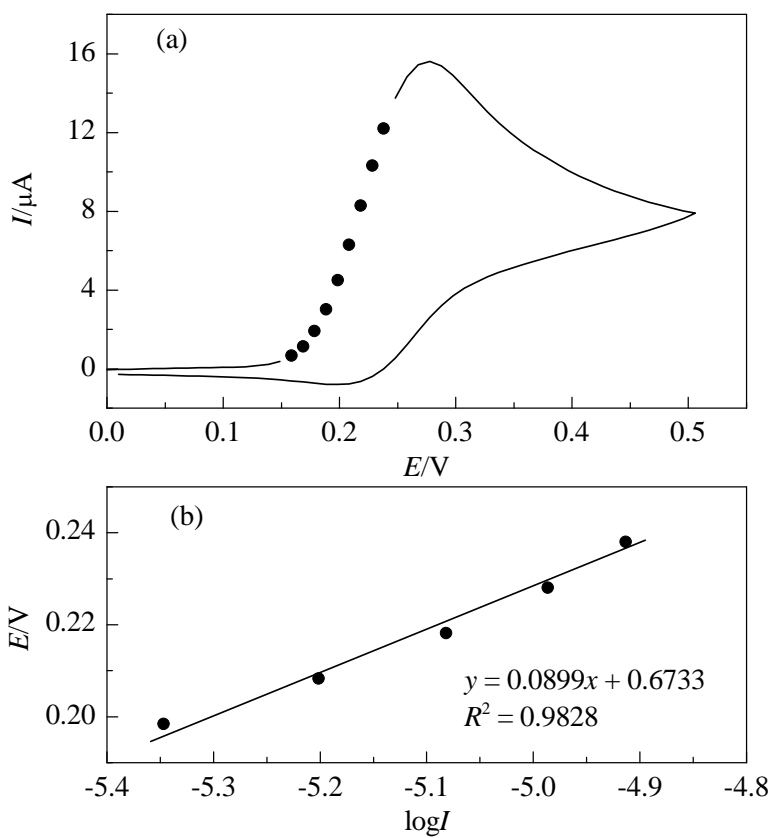

Fig. 5. Tafel plot of $500 \mu \mathrm{mol} / \mathrm{L} 3,4-\mathrm{DHCA}$ at the surface of MWCNTPE in $0.1 \mathrm{~mol} / \mathrm{L}$ PBS (pH 5.0) at a scan rate of $10 \mathrm{mV} / \mathrm{s}$ in the presence of $200 \mu \mathrm{mol} / \mathrm{L}$ GSH. 

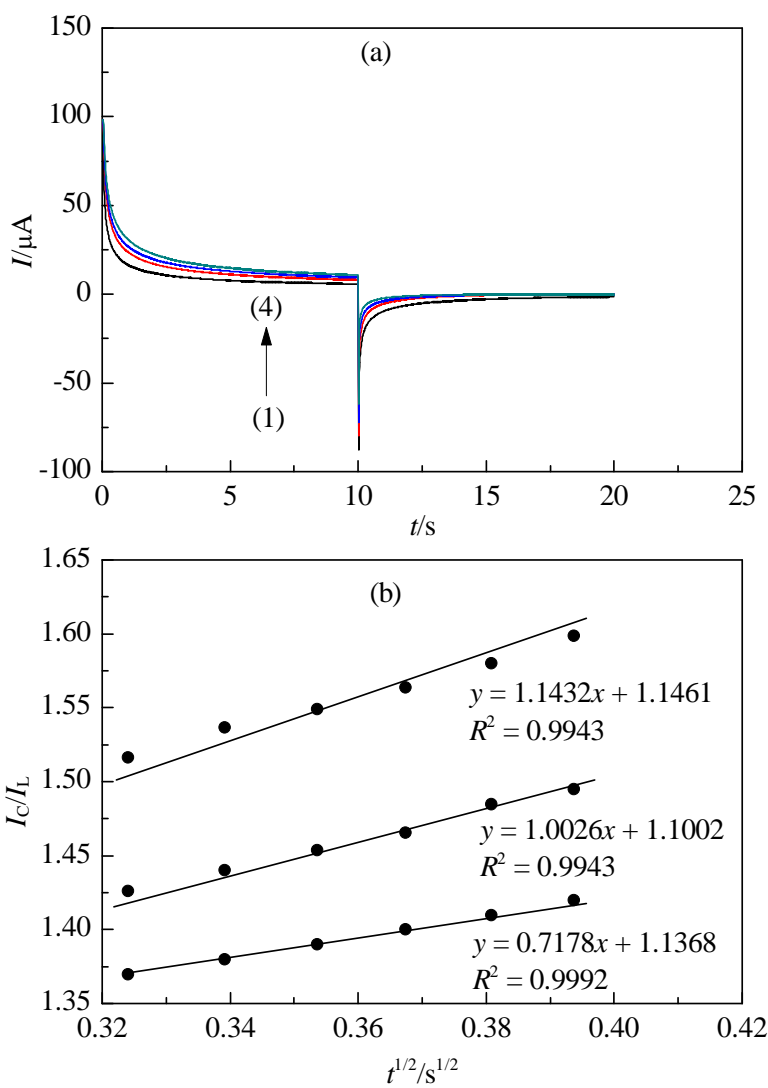

Fig. 6. (a) Chronoamperograms obtained at the MWCNTPE in the absence (1) and in the presence of 200 (2), 300 (3), and $400 \mu \mathrm{mol} / \mathrm{L}(4)$ GSH in a buffer solution (pH 5.0). (b) Dependence of $I_{\mathrm{C}} / I_{\mathrm{L}}$ on the $t^{1 / 2}$ derived from the chronoamperogram data.

Chronoamperometric measurements of GSH at MWCNTPE in the presence of the mediator were carried out by setting the working electrode potential at $0.0 \mathrm{~V}$ (at the first potential step) and at $0.4 \mathrm{~V}$ (at second potential step) versus $\mathrm{Ag} / \mathrm{AgCl} / \mathrm{KCl}_{\text {sat }}$ for different concentrations of GSH in buffered aqueous solution ( $\mathrm{pH} \mathrm{5.0)} \mathrm{(Fig.} \mathrm{6(a)).} \mathrm{The} \mathrm{rate} \mathrm{constant} \mathrm{for} \mathrm{the} \mathrm{chemical}$ reaction between GSH and the mediator at the surface of MWCNTPE, $k_{\mathrm{h}}$, was evaluated by chronoamperometry according to the method of Galus [41]:

$$
I_{\mathrm{C}} / I_{\mathrm{L}}=\pi^{1 / 2} \gamma^{1 / 2}=\pi^{1 / 2}\left(k_{\mathrm{h}} C_{\mathrm{b}} t\right)^{1 / 2}
$$

where $I_{C}$ is the catalytic current of GSH at MWCNTPE in the presence of mediator, $I_{\mathrm{L}}$ is the limited current in the absence of $\mathrm{GSH}$, and $t(\mathrm{~s})$ is the time elapsed. The above equation can be used to calculate the rate constant of the catalytic process, $k \mathrm{~h}$. From the slope of the $I_{\mathrm{C}} / I_{\mathrm{L}}$ versus $t^{1 / 2}$ plot, $k_{\mathrm{h}}$ was obtained for a given GSH concentration (Fig. 6(b)). Based on the values of the slopes, the average value of $k \mathrm{~h}$ was found to be $9.8 \times 10^{2} \mathrm{~mol}^{-1} \mathrm{~L}$ $\mathrm{s}^{-1}$. The value of $k_{\mathrm{h}}$ explains the sharp feature of the catalytic peak observed for catalytic oxidation of GSH at the surface of MWCNTPE in the presence of mediator.

\subsection{Dynamic range and limit of detection}

Linear sweep voltammetry was used to determine the concentration of GSH. The results showed two linear segments with different slopes. For $0.5-2.0 \mu \mathrm{mol} / \mathrm{L}$ of GSH, the regression equation was $\Delta I_{\mathrm{p}}(\mu \mathrm{A})=(3.346 \pm 0.041) C_{\mathrm{GSH}}+(0.146 \pm 0.023)\left(R^{2}\right.$ $=0.992, n=5)$. For $2.0-400.0 \mu \mathrm{mol} / \mathrm{L} \mathrm{GSH}$, the regression equation was $\Delta \mathrm{I}_{\mathrm{p}}(\mu \mathrm{A})=(0.039 \pm 0.002) C_{\mathrm{GSH}}+(6.890 \pm 0.855)\left(R^{2}\right.$ $=0.998, n=6) . C_{\mathrm{GSH}}(\mu \mathrm{mol} / \mathrm{L})$ is concentration of GSH and $\Delta I$ is net electrocatalytic current. The detection limits, according to the definition of $Y_{\mathrm{LOD}}=Y_{\mathrm{B}}+3 \sigma$, was determined as $0.1 \mu \mathrm{mol} / \mathrm{L}$ for GSH.

This detection limit, linear dynamic range, and sensitivity for GSH with the modified electrode is comparable or even better than those obtained by using several other modified electrodes (Table 1).

\subsection{Interference study}

In order to evaluate the selectivity of the proposed method in the determination of GSH, the influence of various foreign species on the determination of $10.0 \mu \mathrm{mol} / \mathrm{L} \mathrm{GSH}$ was investigated. The tolerance limit was taken as the maximum concentration of foreign substances, which caused no more than $\pm 5 \%$ relative error in the determination. The results reported in Table 2 showed that no conventional cations, anions, or organic substances affected the peak current of GSH.

\subsection{Stability and reproducibility}

The repeatability and stability of the MWCNTPE in the presence of 3,4-DHCA were investigated by cyclic voltammetry

Table 1

Comparison of the efficiency of some electrochemical methods for the determination of GSH.

\begin{tabular}{|c|c|c|c|c|c|c|}
\hline Electrode & Modifier & $\mathrm{pH}$ & $\begin{array}{c}\text { LOD } \\
(\mu \mathrm{mol} / \mathrm{L})\end{array}$ & $\begin{array}{c}\text { LDR } \\
(\mu \mathrm{mol} / \mathrm{L})\end{array}$ & $\begin{array}{c}\text { Sensitivity } \\
\left(\mu \mathrm{A} \mu \mathrm{mol}^{-1} \mathrm{~L}\right)\end{array}$ & Ref. \\
\hline Carbon paste & 2,7-BFEF & 7.0 & 0.50 & $0.92-11$ & 1.997 & [43] \\
\hline Carbon paste & $\mathrm{FC}$ & 7.0 & 2.10 & $2.2-3000$ & 0.017 & [19] \\
\hline MWCNTPE & Chlorpromazine & 4.0 & 0.16 & $0.3-18.3$ & 0.541 & {$[44]$} \\
\hline Glassy carbon & Well-aligned/carbon nanotubes & 7.0 & 0.20 & $0.4-16.4$ & 0.010 & [45] \\
\hline Glassy carbon & PQQ/PPy & 8.4 & 13.2 & - & - & [46] \\
\hline Carbon paste & TTF-TCNQ & 7.0 & 0.30 & $5-340$ & - & [47] \\
\hline EPPGE & - & 7.0 & 2.70 & $10-80$ & - & [48] \\
\hline Carbodiimide matrix & Glutathione peroxidase & 7.8 & 15 & $19-140$ & - & [49] \\
\hline Glassy carbon & Horseradish peroxidase & 7.0 & 0.03 & $0.04-90$ & 0.024 & {$[50]$} \\
\hline MWCNTPE & 3,4-DHCA & 5.0 & 0.10 & $0.5-400$ & 3.4346 & this work \\
\hline
\end{tabular}

2,7-BFEF: 2,7-bis(ferrocenyl ethyl)fluoren-9-one; FC: ferrocene; PQQ/PPy: pyrroloquinoline quinine into polypyrrole; TTF-TCNQ: tetrathiafulvalene-tetracyanoquinodimethane; EPPGE: edge-plane pyrolytic-graphite electrode. 
Table 2

Interference study for the determination of $2.0 \mu \mathrm{mol} / \mathrm{L} \mathrm{HCy} \mathrm{under} \mathrm{the} \mathrm{optimized} \mathrm{conditions.}$

\begin{tabular}{lr}
\hline Species & Tolerance limit (W/W) \\
\hline $\mathrm{Li}^{+}, \mathrm{Br}^{-}, \mathrm{NO}_{3}^{-}, \mathrm{SCN}^{-}, \mathrm{SO}_{4}{ }^{2-}, \mathrm{Br}^{-}$, glucose, fructose, lactose , sucrose, $\mathrm{Ca}^{2+}$ & 1000 \\
Hystidine, alanine, phenyl alanine, methionine, glycine, methanol, ethanol, tryptophan, L-theronine, L-isoleucin, L-orinthime & 800 \\
Starch & Saturation \\
Ascorbic acid ${ }^{*}$, urea & 500 \\
\hline
\end{tabular}

*After addition of $1 \mathrm{mmol} / \mathrm{L}$ ascorbic oxidize.

Table 3

Concentration values obtained from the proposed and Elman methods for GSH analysis in hemolysed erythrocyte, urine, and tablets.

\begin{tabular}{|c|c|c|c|c|c|c|}
\hline Sample & Proposed method & Elman method [37] & $F_{\mathrm{ex}}$ & $F_{\text {tab, }(0.05) ; 2,2}$ & $t_{\mathrm{ex}}$ & $t_{\text {tab }}(98 \%)$ \\
\hline \multirow[t]{3}{*}{ Hemolyzed erythrocyte } & $4.55 \pm 0.10$ & $4.87 \pm 0.22$ & 5.5 & 19 & 1.5 & 3.8 \\
\hline & $6.32 \pm 0.22$ & $5.98 \pm 0.62$ & 9.5 & 19 & 1.8 & 3.8 \\
\hline & $5.55 \pm 0.35$ & $5.85 \pm 0.87$ & 10.3 & 19 & 2.5 & 3.8 \\
\hline \multirow[t]{3}{*}{ Urine } & $<$ LOD & $<$ LOD & - & - & - & - \\
\hline & $20.55 \pm 0.72$ & $20.85 \pm 0.87$ & 12.5 & 19 & 2.9 & 3.8 \\
\hline & $30.55 \pm 0.55$ & $30.77 \pm 0.78$ & 11.2 & 19 & 2.7 & 3.8 \\
\hline \multirow[t]{2}{*}{ Tablet } & $9.87 \pm 0.35$ & $9.86 \pm 0.63$ & 6.2 & 19 & 1.7 & 3.8 \\
\hline & $15.10 \pm 0.22$ & $14.32 \pm 0.45$ & 5.8 & 19 & 1.6 & 3.8 \\
\hline
\end{tabular}

The concentration of Hemolyzed erythrocyte was in mmol/L and the concentrations of the urine and tablet samples were in $\mu \mathrm{mol} / \mathrm{L} . F_{\mathrm{ex}}$ : Calculated $F$-value; $F_{\mathrm{tab},(0.05) ; 2,2}$ : Reported $F$ value from $F$-test table with 95\% confidence level and 2/2 degree of freedom; $t_{\mathrm{ex}}$ : Calculated $t ; t_{\mathrm{tab}}(98 \%):$ Reported $t$ value from $t$-student test table with $98 \%$ confidence level.

measurements of 5.0 and $25.0 \mu \mathrm{mol} / \mathrm{LGSH}$. The relative standard deviation (RSD\%) for seven successive assays were $2.2 \%$ and $2.7 \%$, respectively. When using three different electrodes, the RSD\% for four measurements was $3.1 \%$. When the electrode was stored in our laboratory at room temperature, the modified electrode retained $96 \%$ of its initial response after a week and $93 \%$ after $35 \mathrm{~d}$. These results indicate that MWCNTPE has both good stability and satisfactory reproducibility.

\subsection{Determination of GSH in real samples}

In order to evaluate the applicability of the modified electrode for measuring GSH in real samples, GSH values in human erythrocyte, GSH tablets, and urine samples were determined. In addition, the results were compared with those obtained from the spectrophotometric method [37], which is usually used as the standard method for glutathione determination. The results are reported in Table 3 . Clearly, the modified electrode was capable of the voltammetric determination of GSH with high selectivity and good reproducibility.

\section{Conclusions}

3,4-DHCA is a suitable mediator for the electrocatalytic oxidation of GSH in aqueous solution at $\mathrm{pH}$ 5.0. In cyclic voltammetry, the oxidation of GSH occurred at a potential of $300 \mathrm{mV}$ at the surface of the multiwall carbon nanotube paste electrode in the present of 3,4-DHCA, while the oxidation GSH did not take place at the surface of a carbon nanotube paste electrode without 3,4-DHCA up to $+1.0 \mathrm{~V}$. The proposed method gives a selective, simple, and precise new sensor for the voltammetric determination of GSH in real samples such as hemolyzed erythrocyte, GSH tablets, and urine.

\section{References}

[1] Moradi R, Sebt S A, Karimi-Maleh H, Sadeghi R, Karimi F, Bahari A, Arabi H. Phys Chem Chem Phys, 2013, 15: 5888

[2] Devi G S, Prasad M H, Saraswathi I, Raghu D, Rao D N, Reddy P P. Clin Chim Acta, 2000, 293: 53

[3] McDonagh M, Ali L, Kahn A, Flatt P R, Barnett Y A, Barnett C R. Biochem Soc Trans, 1997, 25: 146

[4] Halliwell B. Free Radical Res, 1998, 29: 469

[5] Singh S V, Xu B H, Tkalevic G T, Gupta V, Roberts B, Quiz P. Cancer Lett, 1994, 77: 15

[6] Nagendra P, Yathirajan H S, Rangappa K S, Mohana K N, Nagaraja P. J Indian Chem Soc, 2002, 79: 602

[7] Raggi M A, Nobile L, Giovannini A G. J Pharm Biomed Anal, 1991, 9: 1037

[8] Kamata K, Takahashi M, Terajima K, Nishijima M. Analyst, 1995, 120: 2755

[9] Liang S C, Wang H, Zhang Z M, Zhang X, Zhang H S. Anal Chim Acta, 2002, 451: 211

[10] Kandar R, Zakova P, Lotkova H, Kucera O, Cervinkova Z. J Pharm Biomed Anal, 2007, 43: 1382

[11] Katrusiak A E, Paterson P G, Kamencic H, Shoker A, Lyon A W.J Chromatogr B, 2001, 758: 207

[12] Xu F, Wang L, Gao M N, Jin L T, Jin J Y. Anal Bioanal Chem, 2002, 372: 791

[13] Zhang J Y, Hu Z D, Chen X G. Talanta, 2005, 65: 986

[14] Causse E, Malatray P, Calaf R, Chariots P, Candito M, Bayle C, Valdiguie P, Salvayre R, Couderc F. Electrophoresis, 2000, 21: 2074

[15] Rabenstein D L, Brown D W, McNeil C J. Anal Chem, 1985, 57: 2294

[16] Satoh I, Arakawa S, Okamoto A. Anal Chim Acta, 1988, 214: 415

[17] Ensafi A A, Khayamian T, Hasanpour F. J Pharm Biomed Anal, 2008, 48: 140

[18] Raoof J B, Ojani R, Baghayeri M. Sens Actuators B, 2009, 143: 261

[19] Raoof J B, Ojani R, Kolbadinezhad M. J Solid State Electrochem, 2009, 13: 1411

[20] Ensafi A A, Dadkhah-Tehrani S, Karimi-Maleh H. Drug Test Anal, 2012, 4: 978 


\section{Graphical Abstract}

Chin. J. Catal., 2013, 34: 1883-1889 doi: 10.1016/S1872-2067(12)60661-5

Multiwall carbon nanotube paste electrode with 3, 4-dihydroxy-cinnamic acid as mediator for the determination of glutathione in pharmaceutical and urine samples

Mohsen Keyvanfard*, Hassan Karimi-Maleh, Khadijeh Alizad

Islamic Azad University, Iran;

Graduate University of Advanced Technology, Iran

A novel nanosensor for a sensitive and selective electrochemical sensor for the determination of glutathione in real samples such as tablet, urine, and hemolyzed erythrocyte.

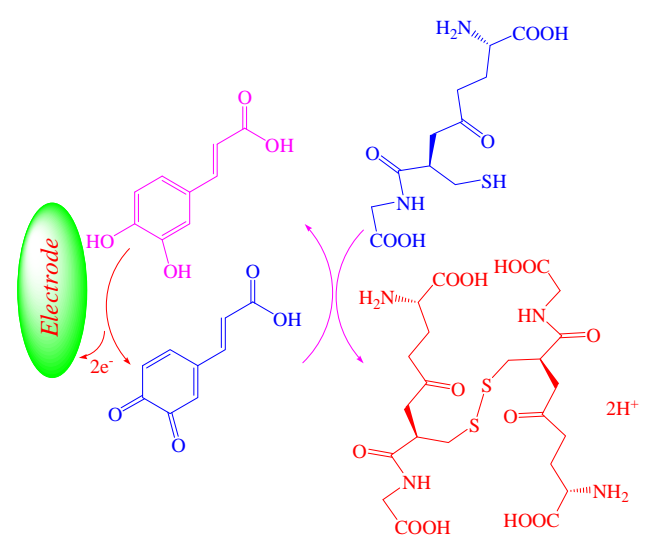

[21] Silber A, Brauchle C, Hampp N.J Electroanal Chem, 1995, 390: 83

[22] Roodbari Shahmiri M, Bahari A, Karimi-Maleh H, Hosseinzadeh R, Mirnia N. Sens Actuators B, 2013, 177: 70

[23] Ensafi A A, Karimi-Maleh H, Mallakpour S. Colloids Surf B, 2013, 104: 186

[24] Fang B, Wei Y, Li M G, Wang G F, Zhang W. Talanta, 2007, 72: 1302

[25] Raoof J B, Ojani R, Karimi-Maleh H. Electroanalysis, 2008, 20: 1259

[26] Iijima S. Nature, 1991, 354: 56

[27] Ijima S, Ichihashi T. Nature, 1993, 363: 603

[28] Goyal R N, Gupta V K, Chatterjee S. Talanta, 2008, 76: 662

[29] Wang G X, Ahn J, Yao J, Lindsay M, Liu H K, Dou S X. J Power Source, 2003, 119: 16

[30] Ensafi A A, Bahrami H, Karimi-Maleh H, Mallakpour S. Chin J Catal (催化学报), 2012, 33: 1919

[31] Ensafi A A, Lotfi M, Karimi-Maleh H. Chin J Catal (催化学报), 2012, 33: 487

[32] Dai H, Hafner J H, Rinzler A G, Colbert D T, Smalley R E. Nature, 1996, 384: 147

[33] Salmanpour S, Tavana T, Pahlavan A, Khalilzadeh M A, Ensafi A A, Karimi-Maleh H, Beitollahi H, Kowsari E, Zareyee D. Mater Sci Eng C, 2012, 32: 1912

[34] Ensafi A A, Karimi-Maleh H.J Electroanal Chem, 2010, 640: 75

[35] Tavana T, Khalilzadeh M A, Karimi-Maleh H, Ensafi A A, Beitollahi H, Zareyee D. J Mol Liq, 2012, 168: 69

[36] Ensafi A A, Karimi-Maleh H, Mallakpour S, Hatami M. Sens Actua- tors $B, 2011,155: 464$

[37] Ellman G L. Archives Biochem Biophys, 1959, 82: 70

[38] Bard A J, Faulkner L R. Electrochemical Methods, Fundamentals and Applications. New York: Wiley, 2001

[39] Ensafi A A, Karimi-Maleh H, Mallakpour S, Rezaei B. Colloids Surf B, 2011, 87: 480

[40] Keyvanfard M, Shakeri R, Karimi-Maleh H, Alizad K. Mater Sci Eng C, 2013, 33: 811

[41] Baghayeri M, Namadchian M, Karimi-Maleh H, Beitollahi H. J Electroanal Chem, 2013, 697: 53

[42] Keyvanfard M, Sami S, Karimi-Maleh H, Alizad K. J Braz Chem Soc, 2013, 24: 32

[43] Raoof J B, Ojani R, Karimi-Maleh H. J Appl Electrochem, 2009, 39: 1169

[44] Ensafi A A, Taei M, Khayamian T, Karimi-Maleh H, Hasanpour F. J Solid State Electrochem, 2010, 14: 1415

[45] Tang H, Chen J H, Nie L H, Yao S Z, Kuang Y F. Electrochim Acta, 2006, 51: 3046

[46] Inoue T, Kirchhof J R. Anal Chem, 2000, 72: 5755

[47] Calvo-Marzal P, Chumbimuni-Torres K Y, Hoehr N F, Kubota L T. Clin Chim Acta, 2006, 371: 152

[48] Moore R R, Banks C E, Compton R G. Analyst, 2004, 129: 755

[49] Rover L R Jr, Kubota L T, Hoehr N F. Clin Chim Acta, 2001, 308: 55

[50] Ruiz-Diaz J J J, Torriero A A J, Salinas E, Marchevsky E J, Sanz M I, Raba J. Talanta, 2006, 68: 1343 